\title{
Preparation of Basic Copper Carbonate Microspheres by Precipitation Method
}

\author{
DU Ying-ji ${ }^{1, a}$, WANG Li-xian ${ }^{1, b^{*}}$,GUO De-hua ${ }^{1, c}$, MA Zhu-qiang ${ }^{2}$, SHEN Long ${ }^{2}$ \\ ${ }^{1}$ Shanghai Institute of Technology, 100 Haiquan Road, Shanghai 201418, China \\ ${ }^{2}$ Shanghai Rongjian Chemical Plant, 269 Chuhua Road, shanghai 201400, China \\ aemail:18721526780@163.com, bemail:wlx@sit.edu.cn, cemail:guodehua2015@163.com
}

\begin{abstract}
Key words: basic copper carbonate; microspheres; particle size; cupric oxide.
Abstract: Basic copper carbonate $\left[\mathrm{Cu}_{2}(\mathrm{OH})_{2} \mathrm{CO}_{3}\right]$ with sphere-like morphology had been prepared via a direct precipitation route by controlled reaction conditions. Crude materials were cupric chloride solution and sodium carbonate solution. The factors like reaction temperature and reaction $\mathrm{pH}$ were studied. Scanning electron microscopy, powder X-ray diffraction, and Fourier transmission infrared spectrometry are used to characterize morphologies, crystal form and structure of the obtained malachite samples, respectively. The result shows: The obtained product is sphere-like malachite. These green basic copper carbonate crystal particles are formed with a diameter of 5.0 6.5 $\mu \mathrm{m}$, when the temperature keeps about $50{ }^{\circ} \mathrm{C}, \mathrm{pH}$ is about 7.0 7.5, and to react for $6 \mathrm{~h}$. And it promotes the crystallization of amorphous basic copper carbonate by adding malachite seeds. Cupric oxide can be obtained with the pyrolysis of as-prepared malachite microspheres, and the microspheres and surface microstructures of the malachite are preserved.
\end{abstract}

\section{Introduction}

For the past few years, the preparation of inorganic crystal or inorganic/organic materials with specific size and morphology has drawn much attention. Even though materials consist of the same chemical constitution, their properties and application will be improved greatly after superfining treatment which leads to different morphologies and structures. Therefore these materials have potential applications, especially in catalysts, medicine,electronics and pigments [1].

Basic copper carbonate ( BCC for short), also named "Malachite", turns the color of malachite green, which is secondary mineral of superficial deposit in nature, and it used to be shown as " $\mathrm{Cu}_{2}(\mathrm{OH})_{2} \mathrm{CO}_{3}$ "; Superfine crystal of BCC with specific size and morphology is used as catalyst [2] with excellent performances.It is also used as a copper source to prepare other copper compounds with special morphologies, such as $\mathrm{CuO}$ [3-5], which has been widely exploited for diverse applications. Superfine $\mathrm{CuO}$ has more excellent performance than its regular powder, which relates to the particle size, morphology and dispersity [6]. Moreover, the precursor is key to control the particle size and morphology of $\mathrm{CuO}$ [7]. Therefore, it is necessary to make a study on the formation process and morphology of superfine malachite.

According to the literatures published, both of hydrothermal method and micro emulsion method have already been used to prepare superfine BBC. Although the BBC particles can be obtained with high crystallinity by hydrothermal method [8], the high temperature is necessary, and the additive agents are always needed. The polymers (such as PEG [9] and PVP [10]) and surfactants (SDS [11]) are always used to control the growth of crystal, which inevitably generated some adulterate products. Present work provides a new routine for the preparation of BCC by the direct reaction of cupric chloride with sodium carbonate with adding seeds. Copper oxide with similar morphology can also be obtained by pyrolysis of the as-prepared malachite.

\section{Experiment}

Reagents and instruments

All reagents are analytical grade.

Dmax-RC type X ray powder diffraction (XRD); S-34000N scanning electron microscope 
(SEM); Fourier transmission infrared spectrometry (FT-IR); BT-9300HT laser granularity analyzer.

Experimental process

First of all, $0.25 \mathrm{~mol}$ cupric chloride was dissolved in distilled water to prepare $0.5 \mathrm{M}$ cupric chloride solution as well as sodium carbonate solution. Then both of them were mixed and added dropwise into a beaker with $250 \mathrm{~mL}$ distilled water at $50^{\circ} \mathrm{C}$ under stirring at $300 \mathrm{r} / \mathrm{min}$. The $\mathrm{pH}$ of reaction solution was kept at $7.0 \pm 0.5$ by controlling the adding rate of the above solutions. All of materials were then added into a beaker in 10 min while keeping stirring at $300 \mathrm{r} / \mathrm{min}$. Then $0.1 \mathrm{~g}$ BCC crystal seeds (made as follows) were added into the mixed solution. After stirring for $0.5 \mathrm{~min}$, the mixed solution was left static at $50^{\circ} \mathrm{C}$ for $6 \mathrm{~h}$ until the presence of green precipitation. The obtained precipitate was filtered and then washed with distilled water so as to remove $\mathrm{Cl}^{-}$in the filter liquor. The content of $\mathrm{Cl}^{-}$could be tested by $\mathrm{AgNO}_{3}$ solution. The product was finally obtained after drying at $110^{\circ} \mathrm{C}$ for $4 \mathrm{~h}$. The reaction formulas were as Eqs. (1):

$$
2 \mathrm{CuCl}_{2}+2 \mathrm{Na}_{2} \mathrm{CO}_{3}+\mathrm{H}_{2} \mathrm{O} \rightarrow \mathrm{Cu}_{2}(\mathrm{OH})_{2} \mathrm{CO}_{3} \downarrow+\mathrm{CO}_{2} \uparrow+4 \mathrm{NaCl}
$$

Preparation of seeds crystal: In a water bath at $50^{\circ} \mathrm{C}, 0.5 \mathrm{M}$ cupric chloride solution and $0.5 \mathrm{M}$ sodium carbonate solution were added simultaneously into a baker with $250 \mathrm{~mL}$ distilled water. The $\mathrm{pH}$ of above mixture was kept at $7.0 \pm 0.5$ by controlling the adding rates. Then the mixed solution was heated to $70^{\circ} \mathrm{C}$ and kept static until the green crystal precipitation could be observed. To take a small amount of the products used as experimental crystal seeds.(SEM images as Figure 4).

Characterization

The obtained malachite samples were confirmed by powder X-ray diffraction (XRD, D/Max 2400 , Rigaku, by a diffractometer equipped with a $\mathrm{Cu} \mathrm{K} \alpha$ radiation source $\lambda=1.5418 \AA$ ) in the $2 \theta$ angles ranging from $10^{\circ}$ to $80^{\circ}$. The morphologies of as-synthesized malachite samples were characterized by using a scanning electron microscope (SEM, S-3400N) with $15 \mathrm{kV}$ of accelerated voltages. FT-IR spectra were recorded on a Fourier transmission infrared spectrometry (FT-IR, NEXUS) at wavenumbers $400-4000 \mathrm{~cm}^{-1}$.

\section{Results and discussion}

Effect of temperature on the particle size of basic copper carbonate

The effect of temperature on the particle size of basic copper carbonate was worked when reaction $\mathrm{pH}$ was $7.0 \pm 0.5$ and reaction time was 6 hours.
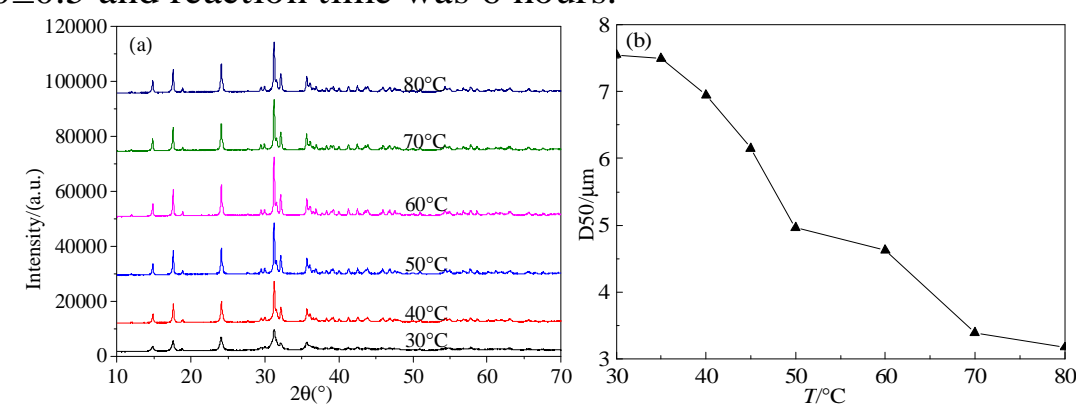

Figure 1 (a) XRD patterns of the prepared basic copper carbonate with various temperature gradients; (b) mean particle diameter (D50) curve graph of the prepared basic copper carbonate with various temperature gradients

Figure 1(a) shows XRD patterns of the prepared basic copper carbonate with various temperature gradients. With rising temperature, peak strength of XRD patterns goes increasing, which indicates that the particle size of products is decreasing according to the Scherrer formula when temperature increases from $30^{\circ} \mathrm{C}$ to $80^{\circ} \mathrm{C}$. Meanwhile, figure $1(\mathrm{~b})$ also shows this result. The formation of crystals mostly depends on two processes, crystal nucleation and growth. The rates of crystal nucleation and crystal growth will be increased, if temperature goes rising. However, the rate of crystal nucleation will go faster than crystal growth. The amount of crystal 
nucleus increase when temperature goes rising. So the crystal particle size decreases as the temperature rises.

Effect of reaction $\mathrm{pH}$ on the degree of crystallinity of basic copper carbonate

The effect of reaction $\mathrm{pH}$ on the degree of crystallinity of basic copper carbonate has been taken when reaction temperature was $50^{\circ} \mathrm{C}$ and reaction time was 6 hours.

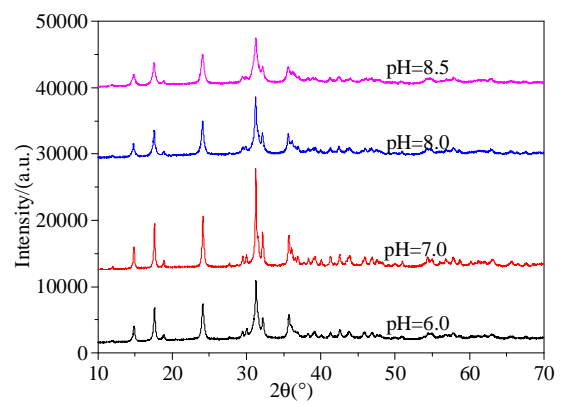

Figure 2 XRD patterns of the prepared basic copper carbonate with different $\mathrm{pH}$ degrees

Figure 2 shows that different reaction $\mathrm{pH}$ degrees have difference effects on XRD patterns of the prepared basic copper carbonate. XRD patterns of the as-prepared samples become broadening when reaction $\mathrm{pH}$ are $6.0,8.0$ and 8.5, which indicates that the samples have low degree of crystallinity. The reason is as follows. The reaction system mainly includes four irons: $\mathrm{Cu}^{2+}, \mathrm{Cl}^{-}, \mathrm{CO}_{3}{ }^{2-}$ and $\mathrm{OH}^{-} ; \mathrm{OH}^{-}$will react with $\mathrm{Cu}^{2+}$ to get $\mathrm{Cu}(\mathrm{OH})_{2}$ doped in the sample when the reaction $\mathrm{pH}$ is kept at 8.0 or 8.5 , and basic copper chloride will be doped in the sample based on the literature when the reaction $\mathrm{pH}$ is kept at 6.0. However, the XRD pattern has higher peak intensity and keeps more sharp-pointed than others when reaction $\mathrm{pH}$ is kept at 7.0. All peaks of this pattern match well with the reported data (JCPDS card File No. 76-0660) and no other impurity peaks can be observed in XRD patterns, which reveals a high purity of monoclinic malachite.

\section{Characterization and discussion}

Malachite $\left(\mathrm{Cu}_{2}(\mathrm{OH})_{2} \mathrm{CO}_{3}\right)$ is monoclinic, space group P21/a with lattice parameters: $a=9.502 \AA, b=11.974 \AA, c=3.240 \AA, \beta=98.75^{\circ}(Z=4)[12]$. XRD patterns of the as-prepared malachite sample are shown in Figure 3. All peaks match well with the reported data (JCPDS card File No. 76-0660) and no other impurity peaks can be observed in XRD patterns, which reveals a high purity of monoclinic malachite.

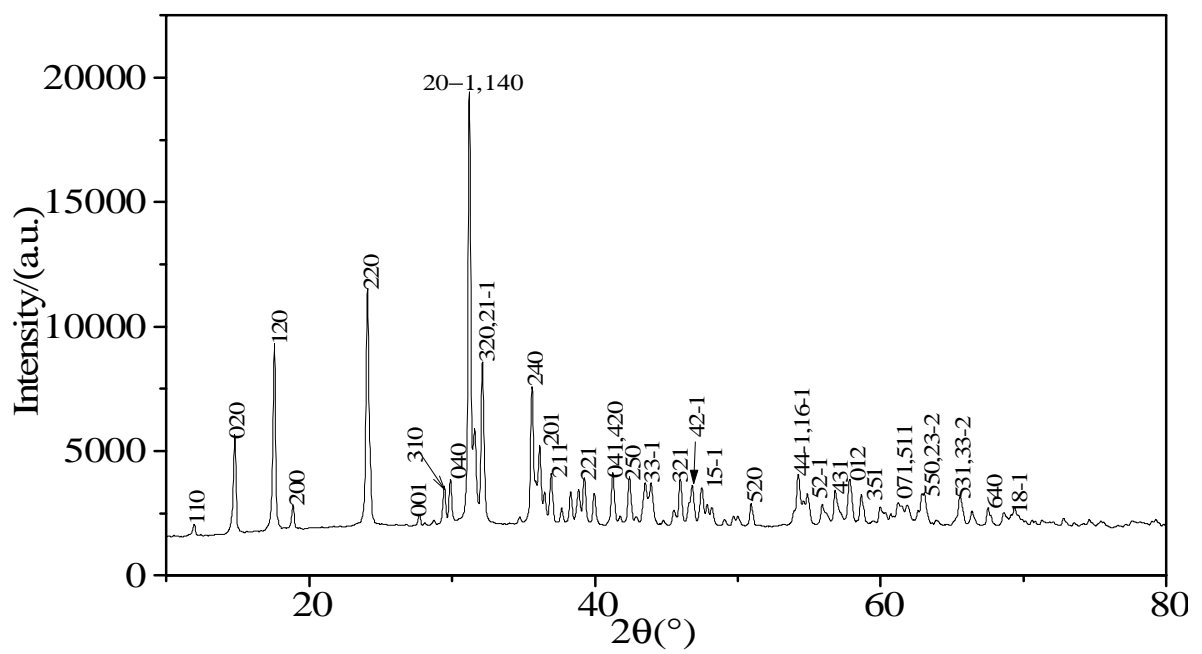

Figure 3 XRD patterns of malachite architecture prepared with seeds at $50{ }^{\circ} \mathrm{C}$ for $6 \mathrm{~h}$.

The surface morphologies of as-prepared malachite are observed by a S-3400N type SEM as shown in Figure 4. It shows that the as-prepared samples are spherical and composed of numerous two-dimensional microchips. The two-dimensional microchips on the surface of sphere are $448 \mathrm{~nm}$ $\times 403 \mathrm{~nm}$ (length $\times$ width). The diameter of these uniform particles is about 5.0 6.5 $\mu \mathrm{m}$ (estimated from SEM images). The particle sizes of the product after adding seeds are more uniform by 
comparing figure 4(a) with figure 4(c). It indicates that the growth of the crystal particle isn't positive to seed crystals. In addition, Seed crystals definitely promote the crystallization of amorphous basic copper carbonate in this study. For instance, crystallization time with seed is $1.25 \mathrm{~h}$, while that without seed is $3 \mathrm{~h}$.
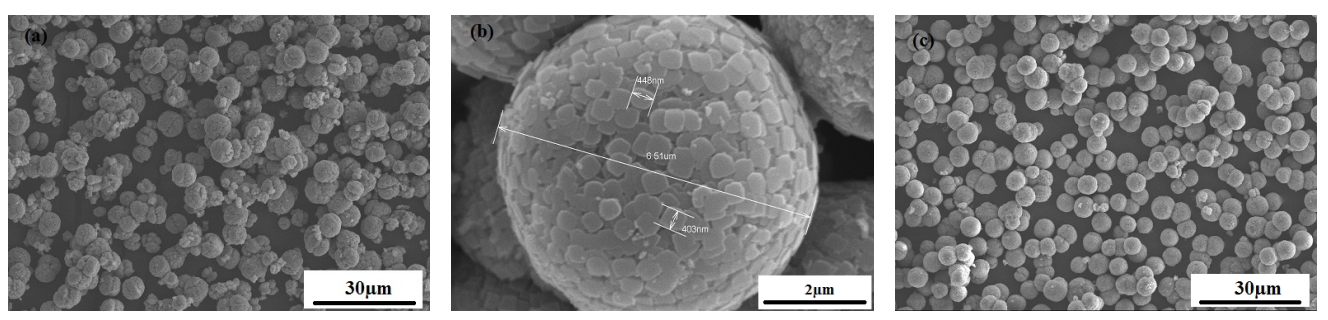

Figure 4 (a)SEM images of malachite samples treated as seeds, (b) and (c) SEM images of malachite prepared with seeds

IR spectra of final malachite are shown in Figure 5, and the spectra coincide well with those reported in the literature[13]. The bands at $3404 \mathrm{~cm}^{-1}$ and $3314 \mathrm{~cm}^{-1}$ are assigned to the $\mathrm{O}-\mathrm{H}$ stretching modes, which shows that there are two crystallographically different $\mathrm{OH}^{-}$ions in the malachite crystal lattice $[14,15]$. The characteristic frequency of $\mathrm{CO}_{3}{ }^{2-}$ is in $1450-1410 \mathrm{~cm}^{-1}$ and $880-860 \mathrm{~cm}^{-1}$. The absorption peaks of $\mathrm{CO}_{3}{ }^{2-}$ may move towards small wavenumber because of cations $\mathrm{Cu}^{2+}$ in malachite. Therefore the bonds at $1496 \mathrm{~cm}^{-1}$ and $1394 \mathrm{~cm}^{-1}$ should be the $\mathrm{C}-\mathrm{O}$ stretching modes, while those at $873 \mathrm{~cm}^{-1}$ and $819 \mathrm{~cm}^{-1}$ belong to the $\mathrm{C}-\mathrm{O}$ bending vibration modes. The peaks at either $505 \mathrm{~cm}^{-1}$ or $428 \mathrm{~cm}^{-1}$ may correspond to the $\mathrm{Cu}-\mathrm{O}$ vibrating modes.

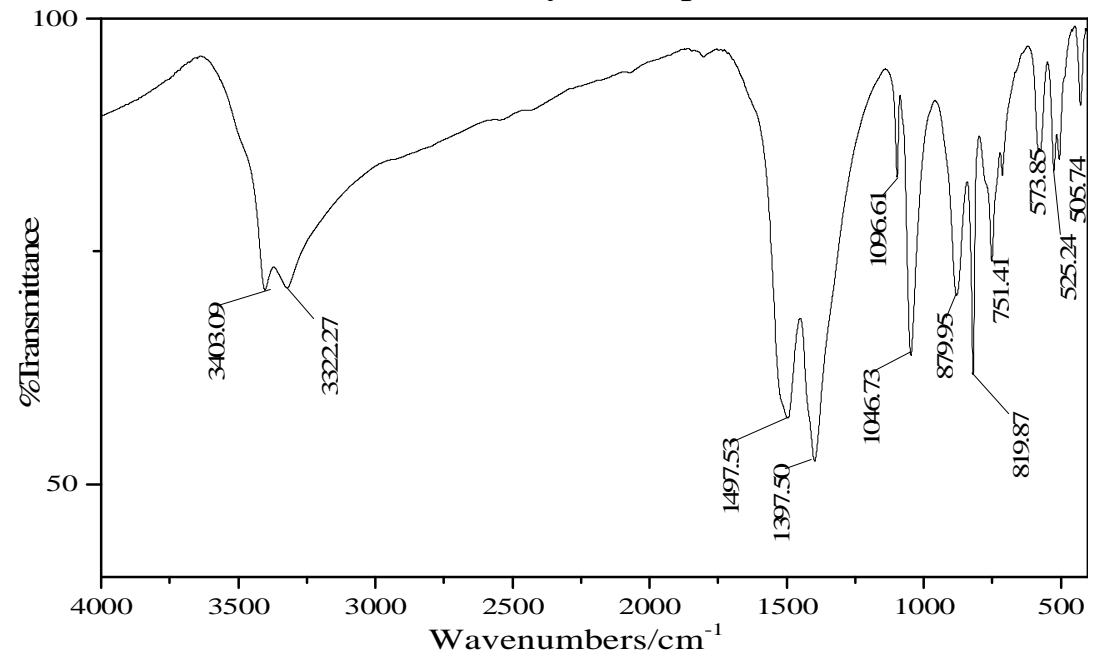

Figure 5 IR spectra of malachite architecture prepared with seals at $50{ }^{\circ} \mathrm{C}$ for $6 \mathrm{~h}$.

Pyrolysis of the as-prepared malachite microspheres

The cupric oxide could be made from the precursor malachite according to Eqs. (2), and the microspheres and its surface microstructures were preserved after malachite was pyrolyzed to $\mathrm{CuO}$ as shown in Figure 6.

$$
\mathrm{Cu}_{2}(\mathrm{OH})_{2} \mathrm{CO}_{3} \rightarrow 2 \mathrm{CuO}+\mathrm{CO}_{2} \uparrow+\mathrm{H}_{2} \mathrm{O}
$$
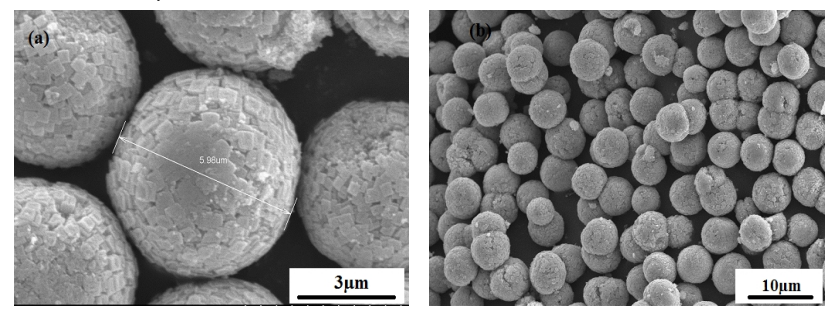

Figure 6 SEM images of product after pyrolysis of as-prepared malachite with the spherical morphology 


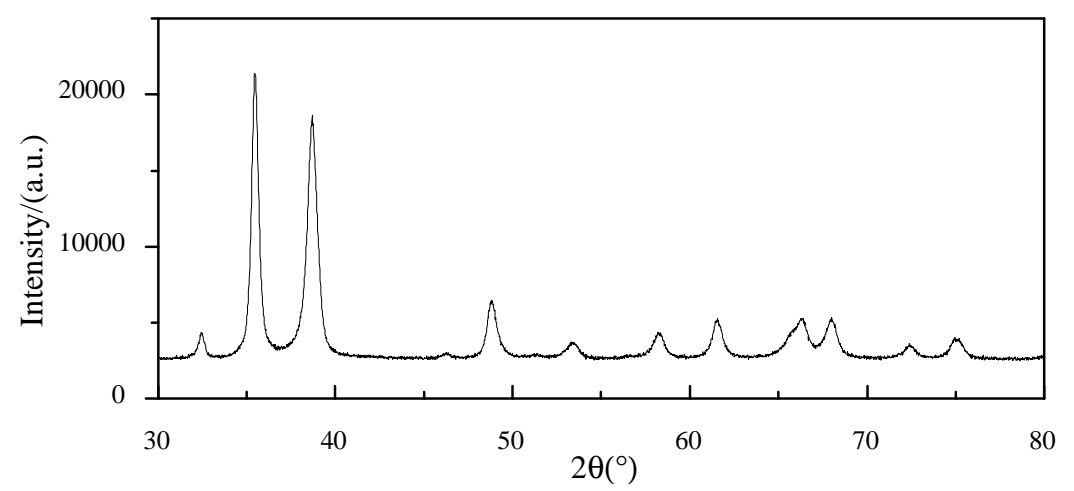

Figure 7 XRD patterns of product after pyrolysis of as-prepared malachite

From the Figure 6, we can see that the microsphere of product with numerous two-dimensional microplatelets paralleling the sphere surface is obtained with thermal treatment at $300^{\circ} \mathrm{C}$ for $5 \mathrm{~h}$. Calefactive rate kept at $10^{\circ} \mathrm{C} / \mathrm{min}$ during heating process. During pyrolysis of malachite microspheres, low calefactive rate is necessary for keeping structures of microspheres unchanged [9]. And all peaks in the XRD patterns match well with the reported data (JCPDS card File No. 45-0937), which indicates that the product after pyrolysis of as-prepared malachite is cupric oxide.

\section{Conclusions}

In summary, the micrometer-scale malachite can be effectively prepared via a simple and mild precipitation with adding seeds to promote the crystallization of amorphous basic copper carbonate. The temperature in reaction plays an important role in controlling the size of malachite particles. The malachite particles are in a uniformly sphere with a diameter of 5.0 6.5 $\mu \mathrm{m}$ at $50^{\circ} \mathrm{C}$, which consists of numerous two-dimensional microplatelets paralleling the sphere surface. The simple precipitation process does not need any inorganic and organic templates, which can easily avoid introducing impurities into the final product. After pyrolysis of malachite precursors at $300^{\circ} \mathrm{C}$ for $5 \mathrm{~h}$ in air atmosphere, copper oxide with similar morphology can be easily obtained.

\section{References}

[1]Rafael Rodriguez-Clemente, Carlos J. Serna, Manuel Ocana, et al. The relationship of particle morphology and structure of basic copper(II) compounds obtained by homogeneous precipitation [J], Journal of Crystal Growth, 1994, 143:277-286.

[2]Gaj Stavber, Zdenko Časar. Basic $\mathrm{CuCO}_{3}$ /ligand as a new catalyst for 'one water' borylation of Michael acceptors, alkenes and alkynes: application to the efficient asymmetric synthesis of $\beta$-alcohol type sitagliptin side chain [J], Applied Organometallic Chemistry, 2013, 27:159-165. [3]Ming-Hui Chang, Hwai-Shen Liu, Clifford Y. Tai. Preparation of copper oxide nanoparticles and its application in nanofluid [J], Powder Technology, 2011, 207:378-386.

[4]Li Dong-sheng, Wang Wen-liang, Wang Yao-yu, et al. Study on the nano-CuO powder made from the precursor synthesized by the precipitation method in mixed solvent $[\mathrm{J}]$, Wuji Huaxue Xuebao(Chinese J. Inorg. Chem.), 2004, 20(5):617-620.

[5]Zibin Hai, Chunhua Zhu, Jianliu Huang, et al. Controllable synthesis of $\mathrm{CuO}$ nanowires and $\mathrm{Cu}_{2} \mathrm{O}$ crystals with shape evolution via $\gamma$-irradiation [J], Inorganic Chemistry, 2010, 49(16):7217-7219.

[6]Wang Wen-liang, Li Dong-sheng, Yue Ke-fen, et al. Effect of precipitant on the morphology and performances of ultrafine powder $\mathrm{CuO}[\mathrm{J}]$, Huaxue Yanjiu Yu Yingyong(Chemical Researchand Application), 2003,15(6):775-778.

[7]Yan Bo, Wang Xin, Shao Chun-hong, et al. CuO nanoparticles:preparation and desulfurization performance at normal temperature [J], Wuji Huaxue Xuebao(Chinese J. Inorg. Chem.), 2007, 
23(11):1869-1874.

[8]Jiasheng Xu, Dongfeng Xue. Fabrication of malachite with a hierarchical sphere-like architecture [J], J. Phys. Chem. B, 2005, 109(36):17157-17161.

[9]Jinhe Sun, Yongzhong Jia, Yan Jing, et al. Formation Process of $\mathrm{Cu}_{2}(\mathrm{OH})_{2} \mathrm{CO}_{3}$ and $\mathrm{CuO}$ hierarchical nanostructures by assembly of hydrated nanoparticles [J], Journal of Nanoscience and Nanotechnology, 2009, 9(10):5903-5909.

[10]Stanka Kratohvil, Egon Matijevic. Preparation of copper compounds of different compositions and particles morphologies [J], J. Mater. Res. 1991, 6(4):766-777.

[11]Bedabrata Saha, Gopal Das. Malachite nanopaticle: A new basic hydrophilic surface for $\mathrm{pH}$ -controlled adsorption of bovine serum albumin with a high loading capacity [J], J.Phy. Chem.C, 2009, 113(35):15667-15675.

[12]Susse P. Verfeinerung der kristallstruktur des malachits, $\mathrm{Cu}_{2}(\mathrm{OH})_{2} \mathrm{CO}_{3}[\mathrm{~J}]$. Acta Crystallogr. 1967, 22:146-151.

[13]Stoilova D., Koleva V., Vassileva V. Infrared study of some synthetic Phases of malachite -hydrozincite series [J]. Spectrochim. Acta A, 2002, 58(9):2051-2059.

[14]Sclunidt M, Lutz H. Hydrogen bonding in basic copper salts: a spectroscopic study of maiachite, $\mathrm{Cu}_{2}(\mathrm{OH})_{2} \mathrm{CO}_{3}$, and brochantite, $\mathrm{Cu}_{4}(\mathrm{OH})_{6} \mathrm{SO}_{4}[\mathrm{~J}]$. Phys. Chem. Miner., 1993, 20(1):27-32.

[15]Lutz H. Structure and strength of hydrogen bonds in inorganic solids [J]. J. Mol. Struct., 2003, 646(1-3):227-236. 